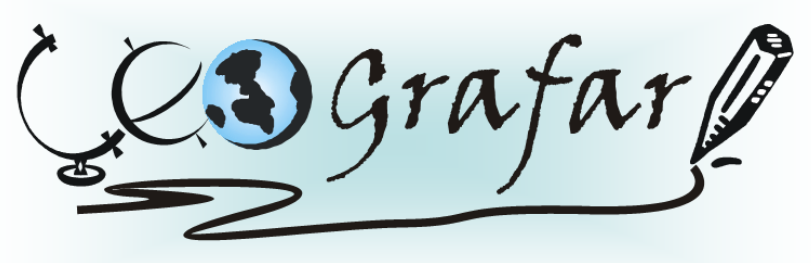

Revista Eletrônica do Programa de Pós-Graduação em Geografia - UFPR

\title{
DELIMITAÇÃO DAS UNIDADES DE PAISAGEM E HEMEROBIA DO BAIRRO CABRAL, CURITIBA/PR - MÉTODOS PARA O PLANEJAMENTO URBANO
}

\author{
LAURA FREIRE ESTÊVEZ 1 \\ JOÃO CARLOS NUCCl
}

\begin{abstract}
Resumo: O planejamento urbano inadequado associado ao acelerado processo mundial de urbanização tem provocado a diminuição da qualidade ambiental, principalmente, nas grandes cidades. Um bom planejamento deveria considerar logo de início o levantamento das diferentes unidades da paisagem (UP) e as transformações provocadas pelo uso humano, procedimentos básicos para uma reflexão sobre os limites e aptidões de cada tipo específico de paisagem (UP). Este trabalho realizou uma avaliação rápida do bairro Cabral - Curitiba/PR, classificando-o em unidades de paisagem acompanhada de uma avaliação do grau de alteração antrópica (hemerobia) de cada UP. Foram delimitadas 7 UP e 2 sub-unidades, com graus de hemerobia que variam entre muito baixo e muito alto dentro do grupo tecno-ecossistemas proposto por Haber (1990). Concluiu-se com a avaliação que o bairro Cabral possui alta hemerobia, mas também tem áreas com coberturas vegetais importantes que atuam como contribuintes nas funções ecológicas e na qualidade ambiental, e que devem ser preservadas.
\end{abstract}

Palavras-chave: planejamento urbano, planejamento da paisagem, unidades de paisagem (UP) e hemerobia.

\section{DELIMITATION OF LANDSCAPE UNITS AND HEMEROBIE IN NEIGHBORHOOD CABRAL, CURITIBA/PR - METHODS FOR URBAN PLANNING}

\begin{abstract}
Inadequate urban planning associated with the accelerated process of global urbanization has led to a decrease of environmental quality, especially in big cities.

Good planning should consider early on a survey of different landscape units (LU) and the changes caused by human use, basic procedures for a reflection on the limits and capabilities of each specific type of landscape (LU). This work conducted a rapid assessment of the neighborhood Cabral Curitiba / PR, classifying it in landscape units together with an assessment of the degree of anthropogenic change (hemerobie) of each LU. 7 LU were delimited and two sub-units with varying degrees of hemerobie between very low and very high within the group techno-ecosystems proposed by Haber (1990). It was concluded with the evaluation that the neighborhood Cabral has high hemerobie, but also has areas with vegetation cover that act as important contributors in the ecological functions and environmental quality, and should be preserved.
\end{abstract}

Key-word: urban planning, landscape planning, landscape units (LU) and hemerobie.

\footnotetext{
${ }^{1}$ Universidade Federal do Paraná - Doutoranda do Programa de Pós-Graduação em Geografia laurafreire.geo@gmail.com

${ }^{2}$ Professor Doutor do Departamento de Geografia UFPR - nucci@ufpr.br
} 


\section{INTRODUÇÃO}

A cidade e o urbano são conceitos distintos, a cidade é material, é a forma, enquanto que o urbano é abstrato, é o conteúdo da cidade. De acordo com Sahr (2010, aula ministrada) a cidade é a "forma de uma aglomeração compacta de moradia e outras funções humanas num determinado espaço" e o urbano é a "expressão funcional e cultural de determinado tipo de vivência social, econômica e política, geralmente com alto grau de diferenciação."

O Brasil se transformou em um país urbano nos últimos 60 anos, mas esse processo se acentuou nas três décadas passadas, pois a grande maioria da população habita as cidades atualmente. O censo demográfico de 2.000 realizado pelo IBGE mostrava que $78 \%$ da população nacional residiam em núcleos urbanos, já o censo 2010 mostrou que essa taxa subiu para 84\% da população nacional. 0 Brasil passou por acelerado processo de urbanização, e esse crescimento populacional nas cidades provocou transformações profundas nas mesmas, tanto positivas quanto negativas.

Alguns aspectos positivos são a queda da mortalidade infantil, o aumento da expectativa de vida, a diminuição do índice de analfabetismo. Quanto aos aspectos negativos temos o aumento da violência generalizada, os problemas com meio ambiente como a ocupação inadequada do solo, a ocorrência de favelas comumente em áreas frágeis, o aumento de enchentes devido a impermeabilidade do solo e ao impedimento das áreas de drenagem, a poluição dos recursos hídricos, a falta de saneamento básico.

Tais problemas poderiam ser sanados com um planejamento urbano adequado a realidade local.

O surgimento do planejamento urbano remonta a época da Revolução Industrial (HALL, 2002). Com a Revolução Industrial ocorreu o inchaço das cidades, e os conseqüentes problemas advindos dessa acelerada urbanização. A expansão das edificações para abrigar os trabalhadores livres teve como resultado, além do trabalho precário, a moradia precária, principalmente quanto as questões sanitárias, pois a mínima infra-estrutura não dava conta da grande densidade populacional. 
No período "liberal", como é chamado esse período por alguns autores, como não havia leis e normas que regulassem a ocupação urbana, essa função ficou para o mercado. Mas como o objetivo do mercado é a obtenção de lucro, a ocupação urbana visava a maximização dos lucros e não se preocupava com a qualidade urbana (SABOYA, 2008). Assim, os espaços abertos que não traziam vantagens econômicas foram deixados de lado.

O planejamento vem como resposta aos problemas existentes nas cidades, principalmente, problemas sanitários e ambientais. Nesse contexto, alteram-se duas questões: 1. da visão estática vigente até então, passa-se a visão dinâmica do fenômeno urbano, que defende que a cidade está evoluindo no tempo; 2. A busca que era pelo modelo de cidade ideal passa para a "solução de problemas práticos, concretos, buscando estabelecer mecanismos de controle dos processos urbanos ao longo do tempo. A cidade real passa a ser o foco." (SABOYA, 2008).

É a idéia do planejamento sistêmico que embasa essas mudanças. Para HALL (2002, p. 6):

(...)uma nova ideia de planejamento como uma série contínua de controles sobre o desenvolvimento de uma área, auxiliados por mecanismos que buscam simular o processo de desenvolvimento de forma que esse controle possa ser aplicado.

Assim, o planejamento funciona como um processo contínuo, no qual os resultados obtidos servem para análise e definição de novos objetivos e metas.

É possível comparar o período "liberal" ocorrido no final do século XIX nos países industrializados com 0 final do século $X X$ para os países em desenvolvimento, pois nos dois períodos e locais diferentes houve crescimento econômico associado a expansão urbana (ANDRADE, 2003), e conseqüentemente impactos sociais e ambientais negativos, poluição e falta de espaços para lazer, por exemplo.

Alguns autores conhecidos como idealistas elaboraram propostas urbanísticas, ainda no final do século XIX, que tentavam solucionar os principais problemas da expansão urbana desordenada, um deles é Ebenezer Howard com o movimento das Cidades-Jardins na Inglaterra. 
A idéia era construir cidades com desenho paisagístico bem definido, limites de crescimento, e com forte interação com o campo, juntando as qualidades da vida urbana com as qualidades do campo. Howard foi além, a proposta dele defendia a vida comunitária e o cooperativismo. Existem algumas cidades na Inglaterra e nos Estados Unidos que tiveram o planejamento voltado à proposta de Howard, por exemplo, Letchworth (primeira Cidade-Jardim) e Village Homes, respectivamente.

Apesar dos ideais de Howard não terem se espalhado por tantos projetos de cidades, foi na década de 1970 que se iniciou a elaboração de empreendimentos com preocupações ecológicas, impulsionados pelo movimento ambientalista. É importante ressaltar que em 1972 houve a Primeira Conferência das Nações Unidas sobre meio ambiente em Estocolmo. Desta década em diante as preocupações ambientais tomaram volume e chegaram a todos os setores da sociedade, assim como no planejamento urbano.

O presente trabalho se desenvolve com base no Planejamento da Paisagem, que pode auxiliar diretamente o planejamento urbano com relação à qualidade ambiental. De acordo com Nucci (2008, p.9) o Planejamento da Paisagem:

(...) seria um instrumento de proteção e desenvolvimento da natureza com o objetivo de salvaguardar a capacidade dos ecossistemas e o potencial recreativo da paisagem como partes fundamentais para a vida humana.

Portanto, o Planejamento da Paisagem serve como importante instrumento no ordenamento do espaço, seguindo os princípios da Ecologia com o objetivo de promover uma adequada distribuição de usos do solo e dos elementos naturais, resultando no aproveitamento eficiente.

A paisagem é então o elemento essencial desse planejamento, é ela que deve ser conhecida, analisada e sintetizada para que se conheça a realidade urbana. $O$ conceito de paisagem proposto por Monteiro (2000) trata a paisagem como uma: 
(...) entidade espacial delimitada, segundo um nível de resolução do pesquisador, a partir dos objetivos centrais da análise, de qualquer modo, sempre resultado de integração dinâmica e, portanto, instável dos elementos de suporte, forma e cobertura (físicas, biológicas e antrópicas), expressa em partes delimitáveis infinitamente, mas individualizadas através de relações entre elas que organizam um todo complexo (sistema), verdadeiro conjunto solidário em perpétua evolução.

A paisagem está sempre em movimento, os elementos componentes e as interrelações entre eles são os responsáveis por essa dinâmica. Segundo os objetivos de estudo se define a escala em que a paisagem será trabalhada. E a partir da análise dos elementos físicos, bióticos e antrópicos é possível observar áreas com características semelhantes, ou áreas homogêneas, que são as unidades de paisagem. Para Fávero et al. (2008) "a unidade de paisagem seria definida por uma síntese de numerosas características e justificada pela redundância ou repetição, que fornecem uma relativa homogeneidade do sistema assim constituído..."

As unidades de paisagem são um instrumento importante para o estudo da paisagem, e o conseqüente planejamento da mesma, segundo Bertrand (2004, p. 144), a delimitação das unidades de paisagem deve ser considerada como um meio de aproximação em relação com a realidade geográfica, o objetivo é pesquisar as descontinuidades objetivas da paisagem. Bertrand (2004, p. 144) afirma que:

(...) é preciso procurar talhar diretamente a paisagem global tal qual ela se apresenta. Naturalmente, a delimitação será mais grosseira, mas as combinações e as relações entre os elementos, assim como os fenômenos de convergência aparecerão mais claramente. A síntese vem felizmente no caso substituir a análise.

A visão sistêmica apresentada por Bertrand reforça a necessidade do pesquisador/observador para o estudo da paisagem. Um software pode fornecer a análise em números e mapas precisos, mas a síntese dos dados, informações e observações só poderá ser feita pelo pesquisador. $\mathrm{Na}$ análise da paisagem as observações e reflexões do pesquisador são fundamentais para a síntese e a integração dos elementos.

A delimitação de unidades de paisagem funciona como uma ferramenta para se conhecer suas potencialidades. Para McHarg (2000 apud FÁVERO, 2008) “(...) 
cada paisagem apresenta uma suscetibilidade intrínseca aos usos da terra podendo eventualmente suportar mais de um tipo de uso antrópico sem comprometimento das funções da natureza". O que define essa suscetibilidade são as características das paisagens, seus limites e aptidões.

A Hemerobia é um conceito que trabalha com as ações antrópicas sobre as potencialidades naturais da paisagem. Esse termo foi cunhado por Jalas (1955), e utilizado por outros autores como Sukopp (1972) e Troppmair (1989), enquanto Monteiro (1978) utiliza a denominação de "derivações antropogênicas". Ambos os termos tratam da diferenciação que vai da naturalidade à artificialidade dos ecossistemas, provocada pela ação humana.

Monteiro (1978, p. 55) diz que "a aspiração em compreender os graus de derivação dos sistemas naturais sob o impacto da tecnologia humana traz importantes implicações quanto às possibilidades das sociedades humanas em planejar seu próprio futuro."

Neste trabalho o termo utilizado é o de hemerobia. E a classificação elaborada é de acordo com Haber (1990), que não cita o termo hemerobia, mas "classifica os tipos de usos da terra de acordo com a diminuição da naturalidade ou aumento da artificialidade, dividindo os ecossistemas em dois grandes grupos: bio-ecossistemas e tecno-ecossistemas" (FÁVERO, et al. 2004).

QUADRO 1 - CLASSIFICAÇÃO DO GRAU DE AÇÃO ANTRÓPICA SOBRE OS USOS DA TERRA PARA HABER (1990).

\begin{tabular}{|c|c|c|}
\hline Grupos & Sub-grupos & Características \\
\hline \multirow[t]{4}{*}{ BIO-ECOSSISTEMAS } & $\begin{array}{l}\text { ECOSSISTEMAS } \\
\text { NATURAIS }\end{array}$ & $\begin{array}{l}\text { Sem influência humana direta e capaz de auto- } \\
\text { regulação. }\end{array}$ \\
\hline & $\begin{array}{l}\text { ECOSSISTEMAS } \\
\text { PRÓXIMOS } \\
\text { NATURAIS }\end{array}$ & $\begin{array}{l}\text { Influenciado pelo ser humano, mas capaz de } \\
\text { auto-regulação. }\end{array}$ \\
\hline & $\begin{array}{l}\text { ECOSSISTEMAS } \\
\text { SEMINATURAIS }\end{array}$ & $\begin{array}{l}\text { Resultantes do uso humano, mas não criado } \\
\text { intencionalmente, com capacidade limitada de auto- } \\
\text { regulação. }\end{array}$ \\
\hline & $\begin{array}{l}\text { ECOSSISTEMA } \\
\text { (BIÓTICO) } \\
\text { ANTROPOGÊNICO }\end{array}$ & 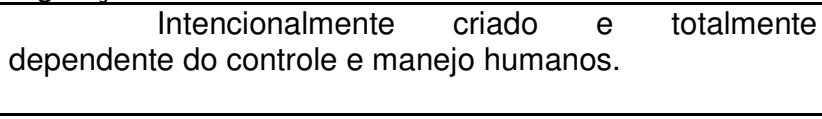 \\
\hline $\begin{array}{l}\text { TECNO- } \\
\text { ECOSSISTEMAS }\end{array}$ & & $\begin{array}{l}\text { Caracterizado pelo domínio de estruturas e } \\
\text { processos técnicos, criados intencionalmente pelo } \\
\text { homem para atividades industriais, econômicas ou } \\
\text { culturais com bio-ecossistemas dispersos em sua malha e } \\
\text { no entorno. }\end{array}$ \\
\hline
\end{tabular}

Fonte: Fávero et al. (2004).

Organização: Laura F. Estêvez (2010). 
Essa classificação de Haber apresenta uma sub-divisão do grupo bioecossistemas em 4 (quatro) sub-grupos, diferenciado-os com relação a interferência humana e quanto a auto-regulação ecológica e/ou dependência antrópica. Já o grupo tecno-ecossistemas não apresenta sub-divisões, e acaba por englobar todas as paisagens que tenham domínio de estruturas e processos técnicos, em uma paisagem urbana essa classificação empobrece a análise. Com sub-grupos seria possível classificar os diferentes graus de inserção tecnológica.

A escolha desse autor se justifica por ele trabalhar com a interação tecnológica sobre os ecossistemas naturais, a avaliação é feita de acordo com o grau de implementação tecnológica na paisagem.

O objetivo do trabalho é classificar as paisagens do bairro Cabral, Curitiba PR, e avaliar suas hemerobias. O bairro Cabral está na área central da cidade de Curitiba - PR (Figura 1), e seus limites são definidos pelo Decreto 774/1975 (IPPUC, 2010): "Ponto inicial na confluência da Avenida Anita Garibaldi e Rua Santo Afonso de Ligório. Segue pelas Ruas Santo Afonso de Ligório, Cel. Amazonas Marcondes, Estrada de Ferro Curitiba - Rio Branco do Sul, Avenida Nossa Senhora da Luz, cerca que delimita os fundos do Graciosa Contry Club, Ruas Glóvis Beviláqua, Camões, Jaime Balão, Bom Jesus, Avenida Anita Garibaldi, até o ponto inicial. $\mathrm{O}$ bairro Cabral apresenta área de 2,04 $\mathrm{Km}^{2}$.

Em 2000 o bairro Cabral apresentava 11.720 habitantes, em 2007 passou para 12.337 habitantes. A população do bairro projetada para 2010 pelo IPPUC é de 12.652, com uma taxa de crescimento decrescente, ainda assim, em 2020 a projeção é de 13.311 habitantes. Com relação a áreas de lazer, no bairro Cabral há 3 (três) jardinetes e 3 (três) praças, que totalizam $5.113 \mathrm{~m}^{2}$ de área (IPPUC, 2010).

\section{MÉTODO}

O trabalho iniciou-se com a delimitação das unidades de paisagem do bairro Cabral (MAPA 2), Curitiba/PR, por meio da utilização de fotografia aéreas (coloridas) na escala 1:8000 de 2002 (IPPUC) e trabalho de campo. Os critérios escolhidos para esta delimitação foram baseados nos diferentes usos do solo: 1. Se área com 
cobertura vegetal (herbáceas, arbustivas ou arbóreas), se solo exposto e/ou impermeável; 2. Se área construída e/ou terrenos vazios; 3. Se construções de 1 (um) pavimento e/ou mais (edifícios); 4. Qual tipo de uso.

Com os critérios definidos, e utilizando-se das fotografias aéreas e de trabalho de campo foi possível delimitar as unidades de paisagem, determinando as áreas homogêneas com relação ao uso do solo.

FIGURA 1: LOCALIZAÇÃO DO BAIRRO CABRAL - CURITIBA/PR.

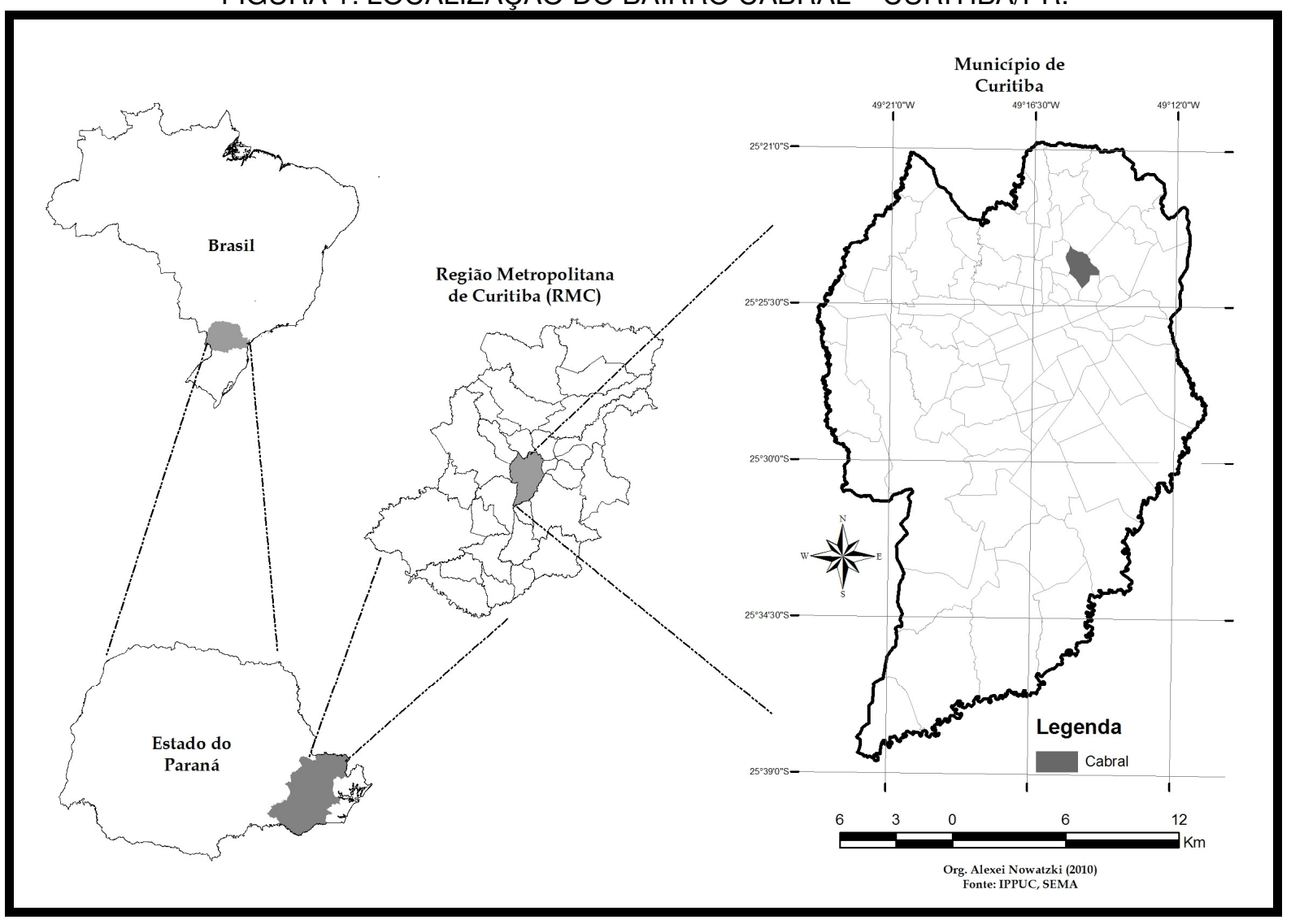

Para a avaliação da hemerobia nas UP foi utilizada a classificação de Haber (1990) adaptada para a área de estudo, por se tratar de área urbana. Os critérios utilizados para a avaliação estão relacionados à inserção tecnológica na paisagem, e esta inserção foi analisada pelos usos do solo existentes e predominantes em cada unidade de paisagem. A opção foi fazer a classificação entre as UP da área em questão. Por exemplo, áreas com fluxo intenso de veículos, áreas de concentração de edifícios, áreas com remanescentes de vegetação, determinam diferentes classes de hemerobia. 


\section{RESULTADOS E DISCUSSÕES}

A população residente dos centros urbanos está cada vez mais afastada do contato com a natureza, isso porque a ausência de um planejamento urbano adequado faz com que não seja dada a devida importância a essa questão, e as áreas construídas dominem a paisagem urbana. Para tanto, um planejamento adequado deve levar em consideração a necessidade da relação homem e natureza, as potencialidade das paisagens e os usos do solo urbano, pensando-se numa (re)estruturação desses usos.

O bairro Cabral foi dividido em 7 unidades de paisagem, e 2 sub-unidades: UP 1. Vias rápidas; UP 2. Avenida Paraná; UP 3. Linha Férrea; UP 4. Alto Padrão; UP 5. Área de uso misto: comercial e residencial; UP 5A. Vazios urbanos; UP 5B. Maior concentração de vegetação arbórea; UP 6. UFPR - Campus de Agrárias; UP 7. Graciosa Contry Club. (Figura 2). 
FIGURA 2: UNIDADES DE PAISAGEM DO BAIRRO CABRAL - CURITIBA/PR.

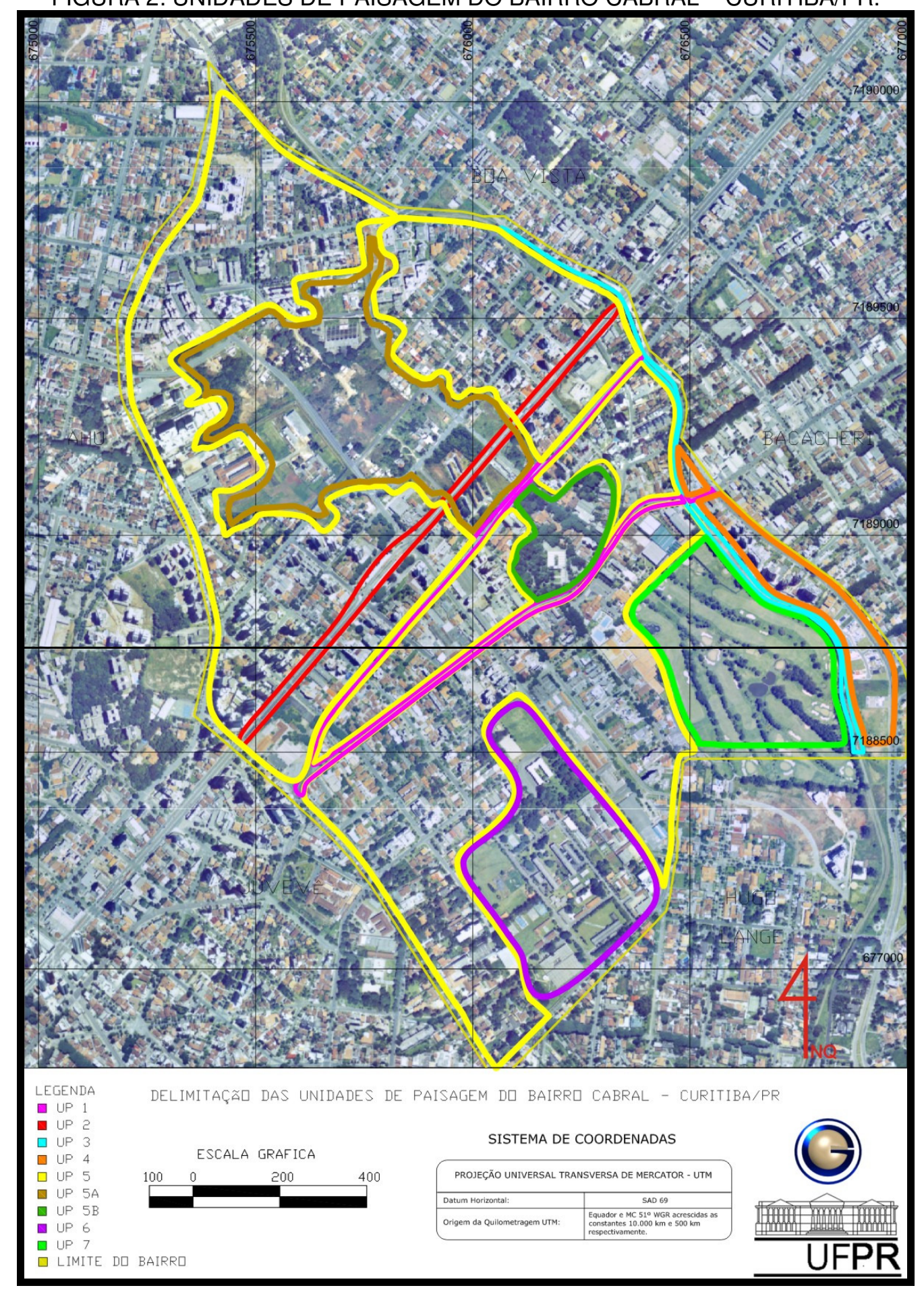

Organização: Laura F. Estêvez e Guilherme Fernandes (2010).

Fonte: IPPUC (2002). 
A avaliação da hemerobia nas unidades de paisagem do bairro Cabral resultou na identificação de 5 classes (Quadro 2 e Figura 3), definidas de acordo com as informações coletadas. Foi realizada uma comparação entre as unidades de paisagem visando identificar as variações de influência humana e o domínio de estruturas e processos técnicos entre elas. As classes definidas para esta classificação pertencem ao grupo tecno-ecossistemas, pois o bairro se caracteriza pelo domínio de tecnologias, e apresenta áreas de bio-ecossistemas na malha e no entorno.

QUADRO 2 - DESCRIÇÃO DAS UNIDADES DE PAISAGEM DO BAIRRO CABRAL, CURITIBA/PR, E CLASSIFICAÇÃO DOS GRAUS DE HEMEROBIA.

\begin{tabular}{|c|c|c|}
\hline UP & DESCRIÇÁO DAS UP & HEMEROBIA \\
\hline 1. Vias rápidas & $\begin{array}{l}\text { Compreende as ruas Deputado Joaquim José Pedrosa e } \\
\text { avenida Munhoz da Rocha, conhecidas como vias rápidas } \\
\text { Centro - Bairros, Centro - Santa Cândida e Centro - Bacacheri, } \\
\text { respectivamente. Uso comercial e residencial, com alto fluxo de } \\
\text { veículos automotivos. Área impermeável. }\end{array}$ & Muito Alta \\
\hline $\begin{array}{l}\text { 2. Avenida } \\
\text { Paraná }\end{array}$ & $\begin{array}{l}\text { Área de uso comercial e residencial (edifícios), com presença do } \\
\text { Terminal de Transporte do Cabral e de via expressa exclusiva } \\
\text { de ônibus e utilitários públicos. Área impermeável. Circulação de } \\
\text { veículos pesados. }\end{array}$ & Muito Alta \\
\hline 3. Linha férrea & $\begin{array}{l}\text { Compreende a área onde a linha férrea atravessa o bairro e a } \\
\text { sua faixa de domínio. Solo compactado. }\end{array}$ & Alta \\
\hline 4. $\quad$ Alto Padrão & Uso do solo residencial, predomínio de edifícios, de alto padrão. & Média \\
\hline $\begin{array}{ll}\text { 5. Área de uso } \\
\text { misto }\end{array}$ & $\begin{array}{l}\text { Uso do solo comercial e residencial (residências e edifícios) com } \\
\text { presença de vegetação dispersa em sua malha e no entorno. }\end{array}$ & Média \\
\hline 5A. Vazios Urbanos & $\begin{array}{l}\text { Uso do solo comercial e residencial, mas com presença de } \\
\text { muitos terrenos vazios, alguns para especulação imobiliária e } \\
\text { outros de propriedade pública. Vegetação herbácea, arbustiva e } \\
\text { arbórea. }\end{array}$ & Baixa \\
\hline $\begin{array}{l}\text { 5B. Maior } \\
\text { Concentração } \\
\text { de Vegetação } \\
\text { Arbórea }\end{array}$ & $\begin{array}{l}\text { Uso do solo comercial e residencial, mas com a maior } \\
\text { concentração de vegetação arbórea da unidade. }\end{array}$ & Baixa \\
\hline $\begin{array}{l}\text { 6. UFPR - } \\
\text { Campus da } \\
\text { Agrárias }\end{array}$ & $\begin{array}{l}\text { Caracteriza-se pela presença de edifícios públicos, } \\
\text { remanescente de vegetação arbórea e áreas de herbáceas. }\end{array}$ & Baixa \\
\hline $\begin{array}{l}\text { 7. Graciosa } \\
\text { Contry Club }\end{array}$ & $\begin{array}{l}\text { Setor do Clube com presença de herbáceas (área permeável) e } \\
\text { fileiras de arbóreas, área relevante pelo tamanho em relação ao } \\
\text { bairro. }\end{array}$ & Muito Baixa \\
\hline
\end{tabular}

Organização: Laura F. Estêvez (2010). 
FIGURA 3: HEMEROBIA NAS UNIDADES DE PAISAGEM DO BAIRRO CABRAL - CURITIBA/PR.

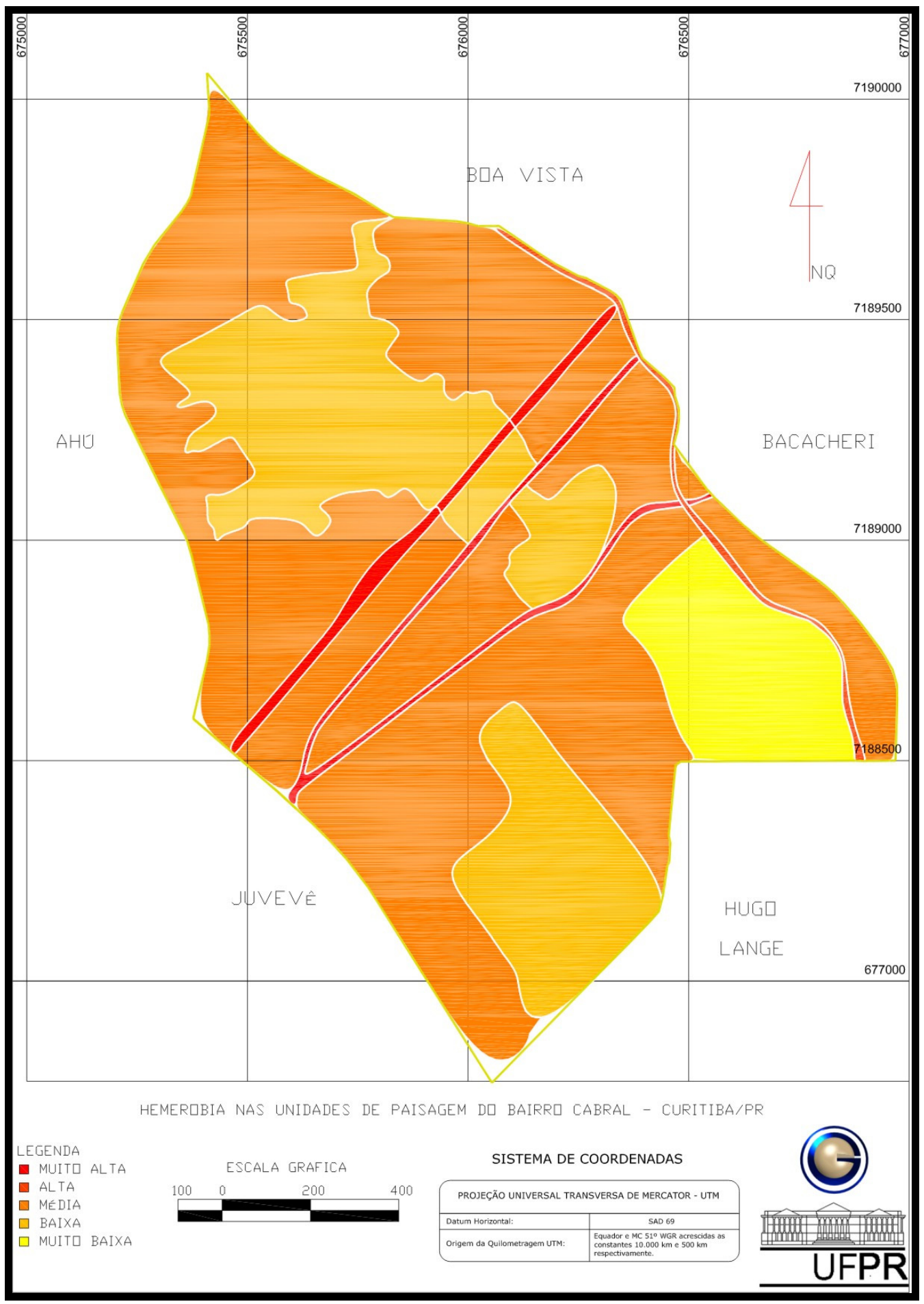

Organização: Laura F. Estêvez e Guilherme Fernandes (2010).

Fonte: IPPUC (2002).

Verificou-se que o bairro se apresenta muito antropizado, com alta hemerobia. Ainda que proporcione áreas de cobertura vegetal importantes, as mais notáveis são: o campo de golfe do Graciosa Contry Club, com predominância de herbáceas e 
fileiras de arbóreas; o Campus da Agrárias da UFPR, que apresenta exemplares arbóreos, isolados e agrupados, que devem ser preservados mesmo com a ampliação dos espaços edificados. A vegetação arbustiva está dispersa pelas ruas, presente na arborização das calçadas, e terrenos do bairro como um todo, sem concentrar núcleos extensos.

Todos esses remanescentes de vegetação são de extrema importância para a qualidade ambiental do bairro Cabral, pois são contribuintes das funções ecológicas.

O mesmo ocorre nos terrenos vazios, que apresentam cobertura vegetal, estes seriam os bio-ecossistemas dispersos na malha do bairro. Com o crescimento imobiliário do bairro estes espaços tendem a desaparecer, o que resultará na queda da qualidade ambiental existente atualmente. A ferrovia e seu entorno também formam biótopos importantes e servem de corredor "ecológico" para várias espécies.

De maneira geral o bairro faz uso misto do solo, misturando atividades comerciais e de serviços com uso residencial. Existem alguns eixos que indicam corredores de edifícios, mas os edifícios também estão distribuídos por todo o bairro.

A rápida análise realizada sobre o bairro Cabral por meio das unidades de paisagem e de suas hemerobias mostra pouca preocupação ambiental no planejamento urbano, porque não existem parques ou bosques na sua área. Mas felizmente existem propriedades privadas que devido ao uso que fazem da terra acabam por atuar como contribuintes das funções ecológicas, como é o caso do Clube. O Campus da Agrárias da UFPR também atua nesse sentido. Essas são áreas de natureza com fins ecológicos e voltados para a qualidade ambiental, que devem ser preservados.

O planejamento voltado para a circulação de pessoas e veículos é muito presente no bairro, notado pela via expressa - Avenida Paraná, e pelas vias rápidas - Rua Deputado Joaquim José Pedrosa e Avenida Munhoz da Rocha. Por localizarse na área central da cidade de Curitiba o bairro está no caminho para outros bairros. Essas vias são negativas para a qualidade ambiental, pois o fluxo de veículos é muito intenso, o que acarreta alta emissão de poluentes, e comumente essas vias possuem pouca cobertura vegetal na arborização das calçadas. 
O bairro Cabral, de acordo com Haber (1990), é um tecno-ecossistema, onde há o domínio de estruturas e processos técnicos com a presença de bioecossistemas dispersos em sua malha e no entorno. Esse tecno-ecossistema tem usos diversos, que diferem quanto à inserção tecnológica sobre a paisagem, por isso a classificação realizada neste trabalho revela o grau hemeróbico nas UP dentro do tecno-ecossistema.

A delimitação de unidades de paisagem e a avaliação dos graus de hemerobia trouxeram um conhecimento relevante para o planejamento da paisagem do bairro Cabral, salientado os usos do solo, a ação antrópica e a natureza nessa paisagem.

As fotografias apresentadas a seguir demonstram algumas unidades de paisagem do bairro Cabral.

FOTOGRAFIA 1: VISTA AÉREA DA AVENIDA PARANÁ (IPPUC, 2004). É POSSÍVEL OBSERVAR O TERMINAL DE TRANSPORTE DO CABRAL E A VIA EXPRESSA - AVENIDA PARANÁ, ONDE HÁ GRANDE FLUXO DE ÔNIBUS. DE USO COMERCIAL E RESIDENCIAL COM PRESENÇA DE EDIFÍCIOS, HÁ POUCA VEGETAÇÃO ARBÓREA.

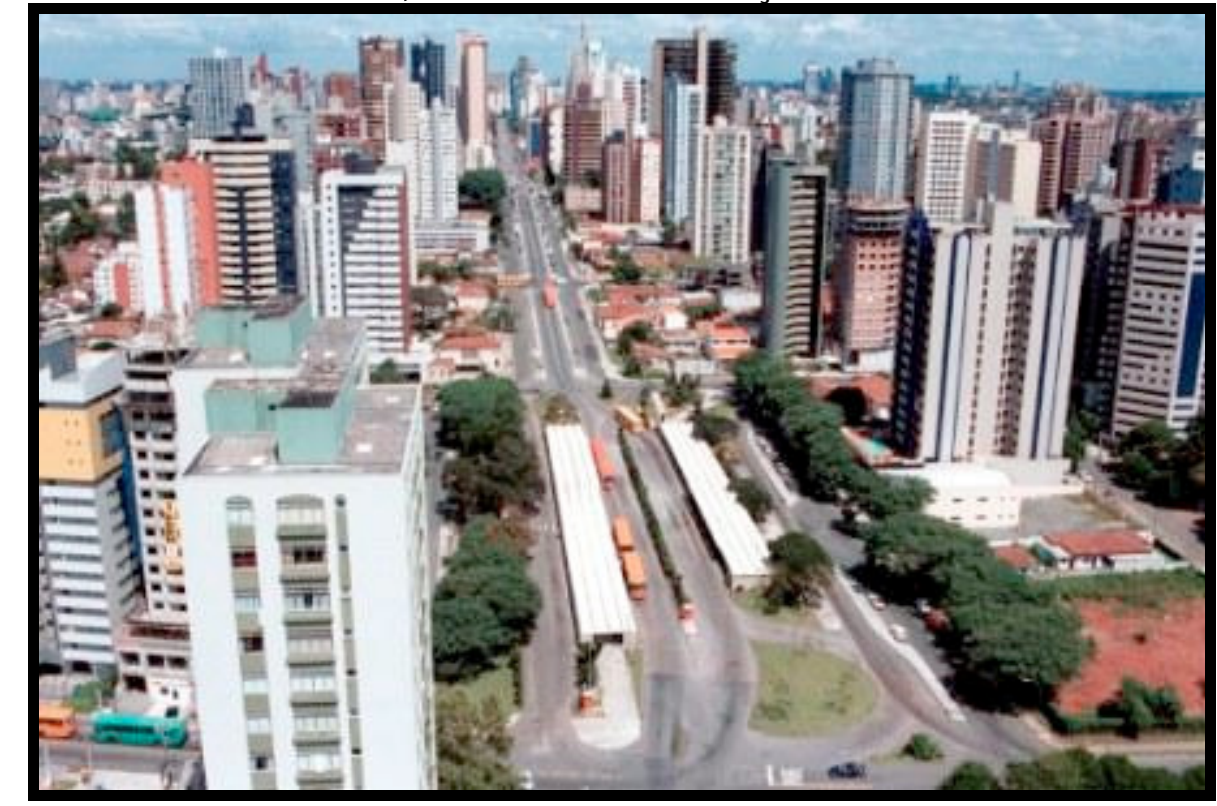

FONTE: IPPUC (2010). 
FOTOGRAFIA 2: VISTA AÉREA DA PRISÃO PROVISÓRIA DO AHÚ. GRANDE ÁREA PERMEÁVEL PRESENTE NO CENTRO DO BAIRRO. VAZIOS URBANOS DE TERRENOS PÚBLICOS COM VEGETAÇÃO HERBÁCEA, ARBUSTIVA E ARBÓREA.

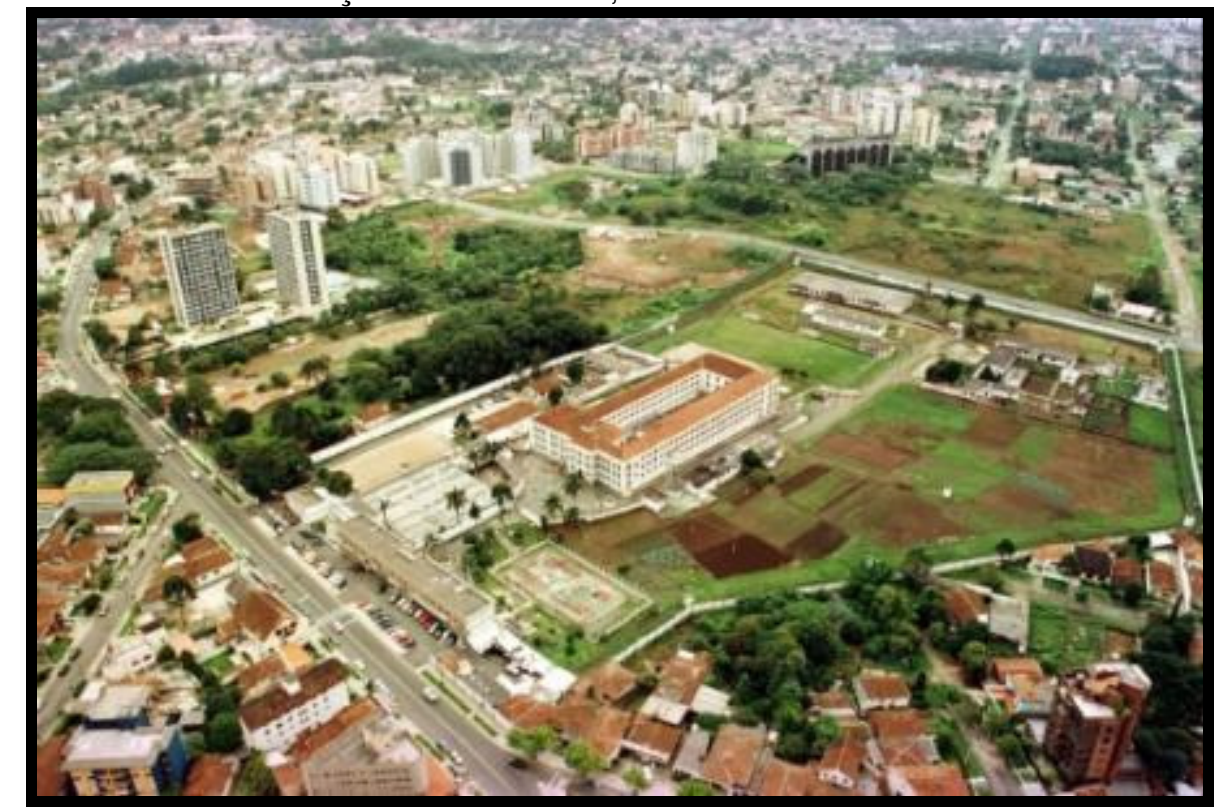

FONTE: IPPUC (2010).

FOTOGRAFIA 3: AVENIDA NOSSA SENHORA DA LUZ (LIMITE DO BAIRRO), FERROVIA E PARTE DO GRACIOSA CONTRY CLUB (VEGETAÇÃO HERBÁCEA E ARBÓREA). O SETOR CENTRAL DA FOTOGRAFIA MOSTRA A ÁREA DE ALTO PADRÃO RESIDENCIAL COM PRESENÇA DE UMA SÉRIE DE EDIFÍCIOS.

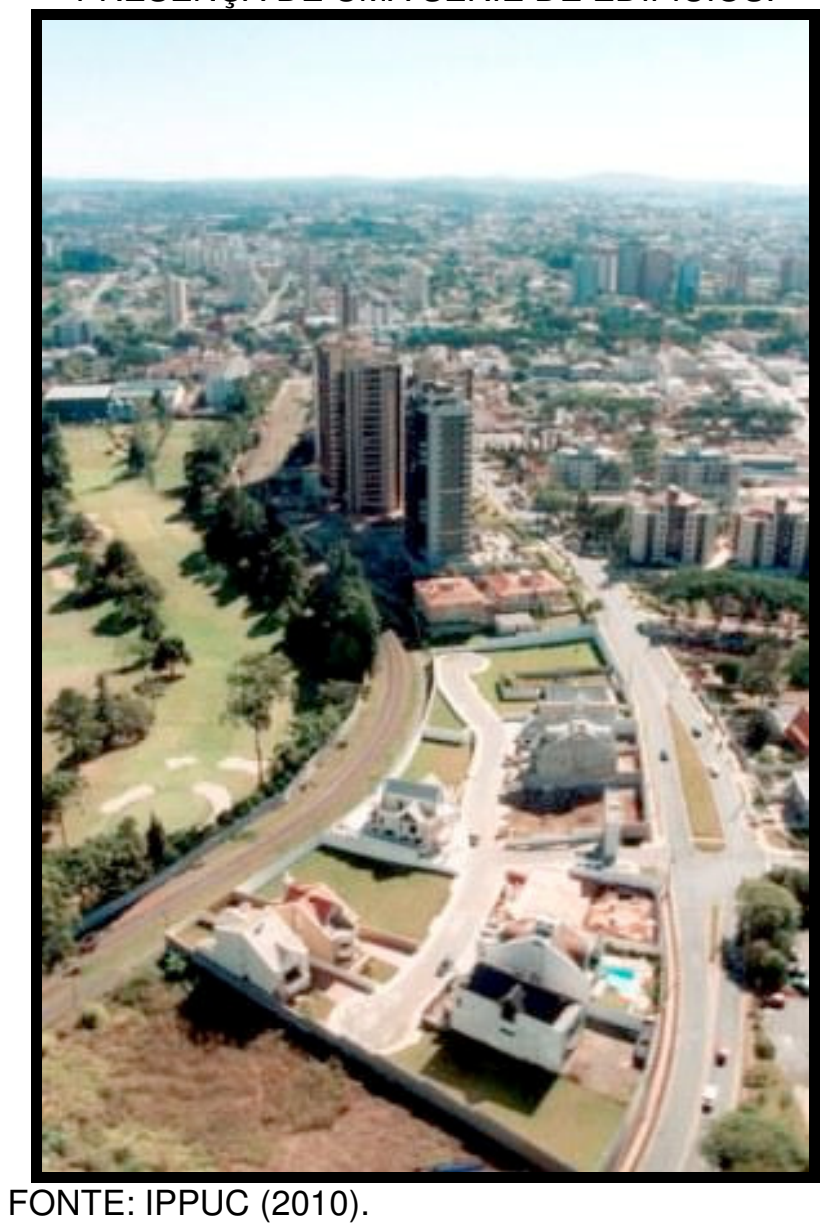




\section{CONCLUSÃO}

As unidades de paisagem do bairro Cabral permitiram identificar de maneira geral algumas de suas características, como o uso do solo e a cobertura vegetal, e as interrelações entre estes elementos e a ação antrópica. Foram delimitadas 7 UP e 2 sub-unidades, que refletem os diferenciados usos da terra.

A hemerobia na área de estudo trouxe informações quanto à influência humana e o domínio de estruturas e processos técnicos sobre a paisagem natural. Foram identificadas 5 classes, que são: muito alta, alta, média, baixa e muito baixa hemerobia em tecno-ecossistemas, de acordo com a proposta de classificação de Haber (1990). Concluiu-se com a avaliação que o bairro Cabral possui alta hemerobia, mas também tem áreas com coberturas vegetais importantes que atuam como contribuintes nas funções ecológicas e na qualidade ambiental, e que devem ser preservadas.

As unidades de paisagem e a hemerobia servem como ferramentas satisfatórias na análise da paisagem urbana, e deveriam ser levantadas logo de início quando de um estudo para futuro planejamento. As duas técnicas contribuem para a classificação da paisagem, portanto trariam bons resultados para o planejamento urbano e para a qualidade ambiental.

O planejamento urbano adequado a realidade de cada área, amparado por estudos do meio físico, como os de delimitação de unidades de paisagem e os de classificação da hemerobia, que são procedimentos básicos para uma reflexão sobre os limites e aptidões de cada unidade de paisagem, pode favorecer a melhoria da qualidade ambiental, através da preservação de áreas verdes e da constituição de possíveis corredores verdes e de biodiversidade dentro das cidades. 


\section{REFERÊNCIAS BIBLIOGRÁFICAS}

BERTRAND, G. Paisagem e geografia física global: um esboço metodológico. 1972. RA'E GA. Curitiba: UFPR, nº. 8, 2004.

FÁVERO, O. A.; NUCCI, J. C.; DE BIASI, M. Hemerobia nas unidades de paisagem da floresta nacional de Ipanema, Iperó/SP: conceito e método. In: IV Congresso Brasileiro de Unidades de Conservação, Anais..., Vol.1, p.550-559, Curitiba, 2004.

FÁVERO, O. A.; NUCCI, J. C.; DE BIASI, M. Hemerobia nas unidades de paisagem da bacia hidrográfica do rio Sorocaba (SP) - Desafios e oportunidades para a conservação da natureza. Geografia. Ensino \& Pesquisa, Anais..., v. 12, p. $2462-$ 2479, Santa Maria: UFSM, 2008.

HABER, W. Using Landscape Ecology in Planning and Management. In: ZOONNEVELD, I.S.; FORMAN, R.T.T. (Eds.) Changing Landscapes: an ecological perspective. New York: Springer-Verlag, 1990, 286p.

HALL, Peter. Urban and regional planning. 4 ed. New York: Routledge, 2002.

IPPUC - Instituto de Pesquisa e Planejamento Urbano de Curitiba. Fotografias aéreas do bairro Cabral, escala 1:8.000, 2002.

Instituto de Pesquisa e Planejamento Urbano de Curitiba - IPPUC.: Curitiba em Dados.

In:http://www.ippuc.org.br/Bancodedados/Curitibaemdados/Curitiba_em_dados_Pes quisa.asp. Curitiba, IPPUC, 2010.

JALAS, J. Hemerobe und hemerochore pflanzenarten. Acta Soc. Pro fauna et flora. 72, $n^{\circ} 11,1955$.

MARIA SOUZA DE ANDRADE, Liza. O conceito de Cidades-Jardins: uma adaptação para as cidades sustentáveis. Arquitextos, São Paulo, 04.042, Vitruvius, nov 2003, In: http://www.vitruvius.com.br/revistas/read/arquitextos/04.042/637.

McHARG, I. Proyectar com la naturaleza. Barcelona, 2000, 197p.

MONTEIRO, C. A. F. Derivações antropogênicas nos sistemas terrestres no Brasil e alterações climáticas. In: Simpósio sobre a Comunidade Vegetal como Unidade Biológica, Turística e Econômica, 1978, Anais..., nº. 15, p. 43-74, São Paulo: ACIESP, 1978.

MONTEIRO, C. A. F. Geossistemas: a história de uma procura. São Paulo: Contexto, 2000, 128p.

NUCCI, J. C. Qualidade ambiental e adensamento urbano: um estudo de ecologia e planejamento da paisagem aplicado ao Distrito de Santa Cecília (MSP). $2^{\underline{a}}$ ed., Curitiba: o Autor, 2008, 150p.

SABOYA, Renato. As origens do planejamento urbano. Urbanidades, 02, 2008 
<http://urbanidades.arq.br/2008/02/as-origens-do-planejamento-urbano/>.

SABOYA, Renato. O surgimento do planejamento urbano. Urbanidades, 03, 2008‥ In: http://urbanidades.arq.br/2008/03/o-surgimento-do-planejamento-urbano/.

SAHR, Cicilian Luiza Lowen. Cidade, Cultura e Planejamento. Disciplina ministrada junto ao Programa de Pós-Graduação em Geografia da Universidade Federal do Paraná, Curitiba, 2010.

SUKOPP, H. Wandel Von Flora and Vegetation in Mitteleuropa unter dem Einfluss dês Menschen. Berichte uber Landwirtschaft, Bd. 50/H.1: 112-139, 1972.

TROPPMAIR, H. Biogeografia e Meio Ambiente. Rio Claro: edição do autor, 1989, 258p.

(Recebido em outubro/2010. Aceito em dezembro/2010) 